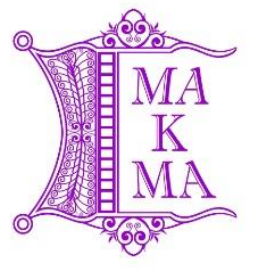

Majalah Kesehatan Masyarakat Aceh (MaKMA) http://ojs.serambimekkah.ac.id/index.php/makma

\title{
GAMBARAN PERILAKU MAHASISWA TENTANG BAHAYA PENGGUNAAN PLASTIK SEBAGAI WADAH MAKANAN DAN MINUMAN PRODI DIII KEPERAWATAN TAPAKTUAN
}

\author{
Asri Jumadewi ${ }^{\bowtie}$ \\ Staf Pengajar Prodi DIII Keperawatan, Poltekkes Kemenkes Aceh, Tapaktuan \\ ${ }^{\bowtie}$ Alamat Korespondensi: Prodi DIII Keperawatan, Poltekkes Kemenkes Aceh, Tapaktuan / \\ asrijumadewi@yahoo.co.id
}

\begin{abstract}
ABSTRAK
Penggunaan plastik cukup populer dikalangan masyarakat. Plastik sering digunakan sebagai kemasan makanan dan minuman. Penggunaan plastik berbahaya bagi kesehatan, khususnya pada janin dan anak. Hal ini dikarenakan plastik mengandung zat tambahan berupa plasticizers. Zat tambahan ini dapat bermigrasi ke dalam makanan dan minuman yang dikemas, apalagi dalam keadaan panas dan berminyak. Masalah ini dapat dihindari dengan mengetahui penggunaan plastik secara benar menurut kode dan jenisnya. Penelitian ini bertujuan untuk mengetahui perilaku mahasiswa tentang bahaya penggunaan plastik sebagai wadah makanan dan minuman. Penelitian ini merupakan penelitian deskriptif. Populasi adalah seluruh mahasiswa Keperawatan Tapaktuan tahun ajaran 2018/2019. Semua populasi dijadikan sampel (total sampling). Pengumpulan data dilakukan melalui wawancara langsung kepada mahasiswa dengan menggunakan kuesioner, yakni 10 pertanyaan untuk pengetahuan dan 10 pertanyaan untuk sikap mahasiswa. Hasil Penelitian menunjukkan bahwa persentase dari 147 mahasiswa yang tergolong berpengetahuan sedang sebanyak 69 orang $(46,94 \%)$ sedangkan sikap mahasiswa yang memiliki sikap positif sebanyak 95 orang $(64,63 \%)$. Saran peneliti agar mahasiswa dapat meningkatkan pengetahuan tentang plastik dan bersikap benar dalam menggunakan plastik sebagai wadah makanan dan minuman.
\end{abstract}

Kata Kunci: Makanan Minuman Kemasan, Perilaku Mahasiswa, Plastik.

Riwayat Artikel 


\title{
DESCRIPTION OF STUDENT BEHAVIOR ABOUT PLASTIC USE HAZARDS AS FOOD CONTAINERS AND PRODUCT DRINKS DIII NURSING IN TAPAKTUAN
}

\begin{abstract}
Utilization of plastic most popular in our society. Plastic often by using as tidiness of food wrapping and beverage. Utilization of plastic danger for health, particulary of the fetus and children. Cause plastic have chemicals in plastic. Plastisizers can be migration to food wrapping and beverage. Especially hot condition and oily. This problem can be avoid with good knowledge about utilization of plastic pursuant to code and classification. The research to know behavior of academy student about danger by using plastic as placed of beverage and food wrapping. This Research is the descriptif. Populations is all nursing academy Tapaktuan 2018/2019 sample to take with gathering by means all direct interview with quesioner technique to gathering spreaading quesioner of 10 question about knowledge and 10 question about attitude of academy student. Result of research indicate that percentage from 147 university student pertained knowledge medium 69 (46,94 \%) academy student have positive attitude is $95(64,63 \%)$. Suggestion of writer is a hope to academy student have to upgrade knowledge about plastic and have good attitude in using plastic as placed of food wrapping and beverage
\end{abstract}

Keywords: Behavior of Academy Student, Plastic, Tidiness of Food Wrapping and Beverage 


\section{PENDAHULUAN}

Perubahan teknologi dan modernisasi dalam berbagai sektor di zaman sekarang demikian pesat sehingga mempengaruhi perilaku manusia dalam berbagai hal. Kemajuan teknologi bidang pangan termasuk salah satunya.Bukan hanya di luar negeri, di Indonesiapun outlet penjualan makanan semakin menjamur dan seni kuliner semakin merebak. Penjualan makanan melalui restaurant, café, pizzeria, bakery shop dan banyak lagi merupakan kelengkapan dari setiap kota besar ${ }^{1}$. Berkembangnya restaurant atau rumah makan, makanan pinggir jalan bahkan penjaja keliling yang menyediakan berbagai makanan siap saji yang menjadi suatu kebutuhan terhadap kehidupan masyarakat saat ini. Untuk itulah peluang bisnis makanan ini menjadi memiliki potensi yang baik untuk dikembangkan, salah satunya menjadi reseller makanan ${ }^{2}$.

Plastik atau styrofoam sering digunakan penjual sebagai kemasan yang memudahkan konsumen ${ }^{3,4,6}$.

Plastik menjadi kemasan makanan yang paling populer digunakan. Banyak pelaku usaha yang menggunakan plastik untuk kemasan makanan mereka. Mulai dari pelaku perusahaan besar yang memproduksi air mineral, makanan ringan, mie instant maupun pelaku usaha kecil seperti home industry, rumah makan dan pedagang kaki lima ${ }^{2}$. Hal ini karena plastik memiliki sifat keunggulan seperti, kuat tapi ringan, tidak berkarat, bersifat termoplastik, yaitu dapat direkat menggunakan panas. Namun, dibalik

\section{METODE}

Penelitian ini merupakan jenis penelitian deskriptif. Penelitian ini bertujuan untuk mengetahui tingkat pengetahuan dan sikap mahasiswa tentang bahaya penggunaan plastik keunggulan plastik, ada juga sisi kelemahan plastik diantaranya tidak tahan panas, bersifat racun karena dapat mencemari produk makanan akibat migrasinya monomer plastik yang akan menyebabkan gangguan kesehatan ${ }^{4,7}$.

Berdasarkan beberapa penelitian yang dilakukan, bahwa Styrofoam dan kemasan plastik jenis LDPE (Low Density Polyethylene) memiliki dampak negatif terhadap kesehatan ${ }^{3,7}$. Perilaku konsumen memiliki hubungan bermakna antara sikap konsumen dengan tindakan dalam penggunaan plastik $^{8}$. Penelitian lain menyebutkan bahwa perilaku mempengaruhi konsumen ataupun penjaja makanan memilih plastik dan Styrofoam sebagai wadah makanan ${ }^{9,10}$. Edukasi pemakaian plastik dianggap penting untuk menghindari resiko kesehatan $^{11}$, bahkan pemerintah telah melarang menggunakan bahan apapun sebagai kemasan pangan yang dinyatakan terlarang menurut hukum ${ }^{22}$. Mengingat masih adanya mahasiswa yang membeli makanan dan minuman panas yang dikemas dengan plastik, bahkan ada pula yang menggunakan botol minuman secara berulang. Berdasarkan uraian latar belakang di atas, maka peneliti tertarik untuk melakukan penelitian terhadap mahasiswa keperawatan yang notabene mengetahui pendidikan kesehatan dengan judul "gambaran perilaku mahasiswa tentang bahaya penggunaan plastik sebagai wadah makanan dan minuman Prodi DIII Keperawatan Tapaktuan".

sebagai wadah makanan dan minuman. Lokasi penelitian di kampus Prodi Keperawatan Tapaktuan yang dilaksanakan dari bulan Maret sampai dengan November 2018. Populasi adalah mahasiswa Keperawatan Tapaktuan tahun ajaran 2018/2019. Sampel yaitu 
keseluruhan populasi berdasarkan kriteria inklusi dan eklusi. Penentuan sampel dari kriteria inklusi adalah seluruh mahasiswa yang terdaftar sebagai mahasiswa DIII Keperawatan Tapaktuan T.A 2018/2019, yaitu keseluruhan populasi (total sampling) yang berjumlah 158 orang mahasiswa. Sedangkan kriteria eklusi adalah mahasiswa DIII Keperawatan Tapaktuan T.A 2018/2019 yang tidak datang pada saat wawancara (interview). Data primer

\section{HASIL}

Berdasarkan penelitian, diperoleh hasil sebagai berikut:

Karakteristik responden meliputi umur dan jenis kelamin. Diketahui bahwa responden terbanyak adalah responden yang berumur antara 17-19 tahun yakni sebanyak 88 orang $(59,86$ \%) [Tabel. 1].

Berdasarkan [Tabel. 2] diketahui bahwa responden terbanyak adalah perempuan sebanyak 120 orang $(81,63$ $\%)$. Berdasarkan hasil skoring dari jawaban responden, maka pengetahuan responden dapat dikatagorikan ke dalam katagori baik, sedang atau kurang.

Pengetahuan berada pada katagori sedang, yaitu sebanyak 69

\section{PEMBAHASAN}

Karakter responden berumur antara 17 tahun sampai dengan 23 tahun. Responden yang berumur paling banyak adalah 17-19 tahun (59,86\%). Jenis kelamin didominasi oleh perempuan yaitu sebanyak 120 orang responden $(81,63 \%)$.

Pengetahuan responden menunjukkan bahwa secara umum responden mengetahui manfaat dan kelebihan plastik untuk kehidupan, yaitu sebagai wadah makanan dan minuman yang mudah di dapat dan fleksibel penggunaannya. Peneliti juga berasumsi, karena selain mudah di dapat, beraneka adalah data yang di peroleh dari hasil wawancara (interview), yang terdiri dari umur, jenis kelamin. Pengetahuan dan sikap diperoleh melalui Pedoman kuesioner. Data Data sekunder adalah data yang diperoleh dari lokasi penelitian berupa gambaran umum kampus pendidikan keperawatan dengan jumlah mahasiswa tahun ajaran 2018/2019.

orang (46,94\%) [Tabel. 3]. Hasil penelitian sikap responden tentang bahaya penggunaan plastik sebagai wadah makanan dan minuman berdasarkan sikap diukur melalui sikap responden tentang penggunaan plastik daur ulang sebagai wadah, cantuman tanda pengenal plastik, aturan menggunakan plastik, bahaya penggunaan plastik sebagai wadah makanan dan minuman panas terhadap kesehatan.

Berdasarkan [Tabel. 4], bahwa katagori sikap responden berada pada katagori sikap negatif, yaitu sebanyak 95 responden $(64,63 \%)$.

bentuk dan warna yang menarik serta tidak mudah pecah (tahan lama). Menurut beberapa penelitian, plastik kresek dan styrofoam menjadi andalan pedagang makanan siap saji karena relatif murah, mudah didapat, tidak korosif, beban ringan dan kuat $^{8,9,11}$. Sedangkan menurut teori, plastik adalah bahan pengemas yang mudah didapat dan sangat fleksibel penggunaannya $a^{3,7}$. Hal ini menyebabkan pengguna memilih plastik sebagai kemasan makanan, sehingga pengguna plastik terus bertambah.

Plastik dapat dikenal oleh responden dengan melihat bentuk 
segitiga di bawah setiap kemasan. Namun, sebanyak 77 orang $(52,38 \%)$ responden belum mengetahui angka yang berada di dalam segitiga kemasan botol plastik, sehingga responden belum mengetahui tentang pemakaian botol plastik kemasan hanya untuk sekali pemakaian, artinya tidak dapat dipakai untuk berulang. Hal ini berdasarkan beberapa studi kepustakaan bahwa untuk mengetahui kode dan jenis botol plastik dapat melihat tanda segitiga dan bertuliskan angka 1 di dalamnya yang ada di setiap kemasan botol plastik ${ }^{7}$. Plastik dari kemasan 1 (PET), 2 (HDPE), 3 (PVC), 4 (LDPE), 5 (PP), 6 (PS) dan 7 (OTHER $)^{3}$.

$$
\text { Setyowati (2017) telah }
$$

melakukan studi kepustakaan tentang bahan-bahan kimia dalam kemasan plastik ${ }^{7}$. Botol jenis PET (Polyethylene Terephthalate) atau berjenis 1 , hanya direkomendasikan untuk sekali pemakaian, dan tidak untuk mengemas makanan dan minuman panas dan berminyak. Bila sering digunakan dan dipakai untuk menyimpan air hangat atau panas, akan mengakibatkan lapisan polimer pada botol tersebut meleleh dan mengeluarkan zat karsinogenik (dapat menyebabkan kanker) ${ }^{5,11}$, dan jenis material ini akan mencair pada suhu 110 ${ }^{0} \mathrm{C}$, mempunyai sifat permeabilitas yang rendah, namun memiliki sifat mekanik yang baik. Begitu juga dengan plastik pembungkus (cling wreb) jenis 3 (PVC) adalah jenis plastik yang mengandung DEHA yang dapat bereaksi dengan makanan yang dikemas apalagi berminyak dan dipanaskan ${ }^{7}$.

Plasticizers, merupakan bahan

berbahaya bagi kesehatan bila mencemari makanan. Plastik dengan jenis dan kode tertentu memiliki keamanan masing-masing sesuai dengan standar penciptaannya ${ }^{3}$. Semakin beraneka ragam warna plastik akan semakin berbahaya bagi kesehatan, karena warna pigmen tersebut akan bermigrasi ke makanan yang dikemas, untuk itu sering dijumpai perubahan warna plastik dalam jangka waktu tertentu. Bukan hanya itu, plastik yang tidak berwarna, juga harus diwaspadai karena semakin jernih, bening dan bersih maka akan semakin banyak plasticizers yang ditambahkan, dan semakin beresiko terhadap kesehatan ${ }^{7}$. Menurut teori yang ada, bahaya plastik antara lain dapat menyebabkan pigmentasi pada kulit dan benjolan, gangguan pada perut dan pada wanita hamil akan menyebabkan kematian bayi dan bayi lahir cacat ${ }^{5,8,10}$.

Sebanyak 78 orang $(53,06 \%)$ tidak mengetahui pentingnya cantuman kode dan jenis plastik. Hal ini menunjukkan bahwa pengetahuan responden tentang aturan pakai dari jenis dan kode yang tertera pada kemasan sekaligus menunjukkan peraturan pemakaian yang benar. Pengetahuan ini akan membentuk perilaku bijak terhadap penggunaan plastik berdasarkan jenis dan kode plastik tertentu yang akan digunakan sebagai wadah makanan dan minuman $^{3,11}$.

Banyaknya responden juga tidak mengetahui ciri plastik dikatakan berbahaya, apabila dibakar akan menghasilkan bau yang berasal dari bahan kimia dioksin, yaitu berbau khas dan keras. Hal ini disebabkan pengetahuan mahasiswa yang kurang tentang informasi bahan berbahaya plastik. Dioksin adalah suatu zat beracun dan merupakan penyebab kanker serta dapat mengurangi sistem kekebalan tubuh seseorang ${ }^{17}$.

Berdasarkan gambaran pengetahuan mahasiswa tentang bahaya penggunaan plastik sebagai wadah makanan dan minuman dapat dikatagorikan berada pada katagori pengetahuan sedang. Asumsi peneliti dimana pengetahuan mahasiswa 
mengenai bahaya penggunaan plastik sebagai wadah makanan dan minuman dipengaruhi oleh sumber informasi, dimana secara kualitas informasi yang diterima masih tergolong kurang. Hal ini sesuai dengan penelitian Siregar (2011), dari 88 ibu rumah tangga pengguna wadah plastik penyimpanan makanan dan minuman di kelurahan Sidorame Timur Kecamatan Medan Perjuangan umumnya berada pada katagori pengetahuan sedang $(73,9 \%)^{16}$.

Pengetahuan mahasiswa ini merupakan hasil dari tahu dan ini terjadi setelah orang melakukan penginderaan terhadap suatu objek tertentu. Penginderaan terjadi melalui panca indera manusia, yakni indra penglihatan, pendengaran, penciuman, rasa dan raba. Sebagian besar pengetahuan manusia diperoleh melalui mata dan telinga ${ }^{13}$.

Pengetahuan dapat diperoleh dari pengalaman sendiri maupun orang lain ${ }^{13}$. Pengetahuan (kognitif) merupakan domain yang sangat penting dalam membentuk tindakan seseorang (over behavior $)^{15}$. Pengetahuan bersumber dari informasi, jika informasi yang diterima benar maka akan membentuk domain pengetahuan yang benar. Dari hasil penelitian ini menggambarkan bahwa sebagian besar pengetahuan mahasiswa berada dalam katagori pengetahuan sedang. Maka dapat disimpulkan bahwa informasi yang diterima mahasiswa tentang bahaya penggunaan plastik sebagai wadah makanan dan minuman adalah belum benar.

\begin{tabular}{lrrr}
\multicolumn{1}{c}{ Hasil } & penelitian & dari 147 \\
mahasiswa, & sebanyak & $41,50 \%$ \\
menginginkan & adanya & peraturan
\end{tabular} penggunaan plastik sebagai kemasan sehari-hari adalah sebanyak 61 orang $(41,50 \%)$. Adanya keinginan mahasiswa menggganti kemasan plastik dengan kemasan yang alami seperti daun pisang sebanyak 43,54\%. Kemasan plastik tidak digunakan sebagai tempat makanan dan minuman panas sebanyak 51 orang (34,69\%). Asumsi peneliti bahwa pengetahuan mahasiswa yang tergolong sedang akan menyebabkan perubahan sikap yang positif. Hal ini sesuai dengan penelitian Sumbung (2012) dari 70 penjual gorengan di Kota Manado sebanyak $87,1 \%$ memiliki sikap baik ${ }^{17}$. Penelitian Ilmiawati (2017) tentang edukasi pemakaian plastik sebagai kemasan makanan dan minuman serta resiko terhadap kesehatan pada komunitas kecamatan Bungus di Padang menyebabkan perubahan sikap terhadap penggunaan plastik yang baik dan benar ${ }^{11}$.

Hal ini memperlihatkan pengetahuan responden secara umum dapat mengubah perilakunya dalam penggunaan plastik sebagai wadah makanan dan minuman panas. Sikap merupakan reaksi atau respon yang masih tertutup dari seseorang terhadap suatu stimulus atau objek tertentu yang sudah melibatkan faktor pendapat dan emosi yang bersangkutan (setuju atau tidak setuju) $^{14}$.

Sikap responden terhadap pernyataan plastik daur ulang sebagai kemasan makanan dan minuman ada sebanyak 82 orang $(55,78 \%)$ yang tidak setuju,. Hal ini disebabkan, sebagian plastik diproduksi dari proses daur ulang ${ }^{3}$. Berdasarkan penelitian Herman yang dikutip Setyowati (2017) bahwa, hasil daur ulang dapat menyebabkan kanker karena mengandung dioktifalat (DOP) yang bersifat toksin ${ }^{7}$. Banyaknya responden yang tidak setuju dengan pencantuman tanda pengenal plastik sebanyak 64 orang $(43,54 \%)$ dikarenakan pengetahuan responden secara umum tidak merasa penting dicantumkan, sehingga sikap responden tidak menyetujuinya. Hal ini akibat pengetahuan responden belum mengetahui ada banyaknya jenis dan 
kode plastik yang masing-masing berbeda ketahanan dan kemanan sebagai wadah makanan dan minuman, yaitu antara lain plastik dengan kode dan jenis 1 (PET), 2 (HDPE), 3 (PVC), 4 (LDPE), 5 (PP), 6 (PS) dan 7 (OTHER) 3 .

$$
\text { Sikap selanjutnya juga }
$$

ditunjukkan dalam pernyataan makanan didinginkan terlebih dahulu sebelum dikemas dalam wadah plastik, secara umum responden memberikan jawaban yang sama kurang setuju dan tidak setuju, yaitu 58 orang $(39,46 \%)$. Hal ini sesuai dengan pengetahuan responden yang boleh menggunakan plastik untuk kemasan makanan panas. Padahal, menurut teori yang ada, plastik bersifat termoplastik, artinya dapat meleleh pada suhu tertentu dan melekat mengikuti perubahan suhu ${ }^{5,7,10}$.

Kemasan plastik memiliki kelebihan yang praktis, murah, fleksibel penggunaannya, sebanyak 58 orang $(39,46 \%)$ bersikap setuju, hal ini sesuai dengan distribusi pengetahuan manfaat plastik yang diketahui responden sehingga, responden bersikap setuju. Selain plastik sangat mudah didapatkan, dan fleksibel penggunaannya ${ }^{7}$, plastik juga sangat mudah dibuat dengan teknik kopolimerisasi, laminasi dan ekstrusi ${ }^{8,11}$.

Plastik yang memiliki ciri lebih kuat, jika ditekan akan kembali kesemula layak digunakan, banyak yang bersikap tidak setuju, yaitu sebanyak 86 orang $(58,50 \%)$. Belum tahunya jenis dan kode plastik membuat para responden bersikap tidak setuju, yang mana penggolongan plastik kuat, kaku termasuk golongan 2, 4, 5 dan 7, polimer merupakan gabungan dari berbagai monomer yang akan membentuk rantai yang sangat panjang. Bila rantai tersebut dikelompokkan bersama-sama dalam suatu pola yang sejajar, akan membentuk kristalin dengan sifat yang lebih keras dan tegar ${ }^{7}$ Golongan yang direkomendasikan sebagai kemasan makanan dan minuman adalah 1, 2, 4 dan $5^{3,5}$. Kemasan makanan panas berbahaya untuk kesehatan, banyak yang bersikap tidak setuju ada 68 (46,26\%), hal ini disebabkan pengetahuan responden di awal secara umum tidak berbahaya bagi kesehatan. Pengetahuan inilah yang menyebabkan responden bersikap tidak setuju. Teori yang ada, bahwa semakin panas makanan yang dikemas dengan plastik maka akan semakin bahaya, karena tingkat kontaminasi akan semakin tinggi ${ }^{8,18}$. Pertanyaan terakhir, adalah tentang sikap terhadap plastik botol mineral digunakan sekali pemakaian, jawaban responden didominasi oleh tidak setuju sebanyak 86 orang $(58,50 \%)$. Sesuai dengan pengetahuan responden banyak yang dua kali pemakaian. Padahal, botol mineral merupakan kemasan plastik dengan jenis 1 (PET), rekomendasi hanya untuk sekali pemakaian $^{3,5,10}$.

Gambaran katagori sikap responden tentang bahaya penggunaan plastik sebagai wadah makanan dan minuman berada pada katagori sikap positif, yaitu sebanyak 95 responden (64,63\%). Asumsi peneliti bahwa mahasiswa memiliki sikap dengan katagori positif karena berada dalam pendidikan kesehatan sehingga, mahasiswa bersikap preventif dalam hal bahaya yang dapat mengganggu kesehatan, dibuktikan sebagian besar mahasiswa menginginkan alternatif kemasan makanan yang aman. Sesuai dengan penelitian dari 40 konsumen yang berada di Amaliun Foodcourt sebanyak $82,5 \%$ dikatagorikan memiliki sikap baik yang menggambarkan ingin mendapatkan kemasan makanan yang aman $^{6}$. Sikap positif diasumsikan sebagai sikap yang baik. Hal ini berdasarkan penelitian Damanik (2012), bahwa dari 100 konsumen pengguna plastik kresek hitam daur ulang sebagai wadah makanan siap santap di Pusat 
Pasar Tavip Binjai berada dalam perilaku sikap baik $(95 \%)^{8}$. Penelitian Siregar (2011), dari 88 ibu rumah tangga pengguna wadah plastik penyimpanan makanan dan minuman di kelurahan Sidorame Timur Kecamatan Medan Perjuangan umumnya berada pada katagori sikap baik $(84,1 \%)^{16}$.

Pengetahuan katagori sedang dan baik akan menghasilkan sikap positif, dimana sikap merupakan reaksi atau respon yang masih tertutup oleh seseorang terhadap suatu stimulus atau objek. Sikap belum merupakan suatu tindakan atau aktifitas, akan tetapi merupakan "predisposisi" tindakan atau perilaku ${ }^{13}$. Perilaku kesehatan pada dasarnya adalah sikap dan kebiasaan yang terbiasa di bidang kesehatan yang diakibatkan oleh adanya stimulus yang selalu mengikat dirinya ${ }^{12}$.

Perubahan perilaku kesehatan terjadi karena adanya proses korelasi antara stimulus (sebagai independent variable) terhadap respon yang terjadi

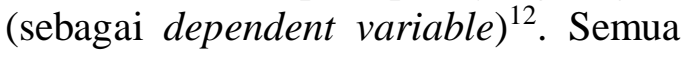

\section{KESIMPULAN DAN SARAN}

Penelitian ini diperoleh beberapa kesimpulan yaitu: Gambaran pengetahuan mahasiswa prodi keperawatan tapaktuan tentang bahaya penggunaan plastik sebagai wadah makanan dan minuman adalah berada pada katagori sedang sebanyak 69 orang $(46,94 \%), 62$ orang $(42,18 \%)$ pada katagori baik dan 16 orang $(10,88 \%)$ pada katagori kurang. Gambaran sikap mahasiswa prodi keperawatan tapaktuan tentang bahaya penggunaan plastik sebagai wadah makanan dan minuman adalah katagori positif sebanyak 95 orang $(64,63 \%)$ dan 52 orang $(35,37 \%)$ katagori negatif.

Berdasarkan kesimpulan, maka disarankan beberapa hal, yaitu: jenis perilaku kesehatan bernilai baik bagi jaminan kesehatan, bila kita perhatikan selalu dikaitkan dengan konsep pencegahan menghindari penyakit (konsep fivelevel ofpreventition against deseases oleh Leavel and Clark) yang melahirkan istilah Health Prevention Behaviour Perilaku kesehatan seseorang biasanya memiliki kecenderungan dipengaruhi oleh kepercayaan. Karenanya, mengubah perilaku kesehatan yang semula nonmedis melalui pendidikan kesehatan harus didahului oleh konsep knowledgeattitude-practice ${ }^{12}$.

Penelitian ini menyimpulkan bahwa, sikap (attitude) responden berada dalam katagori positif terhadap penggunaan plastik sebagai wadah makanan dan minuman, karena sikap pendidikan kesehatan bukan saja dibentuk oleh pengetahuan mahasiswa, namun juga dipengaruhi oleh aspek emosional, pengalaman dan kondisi lingkungan mahasiswa berada.

Meningkatkan pengetahuan mahasiswa tentang plastik dan bahaya menggunakan plastik sebagai wadah makanan dan minuman. Bersikap benar dalam menggunakan plastik sebagai wadah makanan dan minuman, tidak mengemas makanan panas/berminyak, melainkan menggunakan alternative secara alami seperti daun pisang atau memakai bahan kaleng/stainless. Melanjutkan penelitian tentang plastik, seperti: Meneliti kandungan bahan plastik yang dapat bermigrasi ke dalam makanan/minuman panas dan bahaya yang ditimbulkan. Mengurangi pemakaian plastik terutama kepada para pedagang makanan/minuman yang banyak menyumbang sampah plastik. 


\section{DAFTAR PUSTAKA}

1. Bartono, 2010. Tata Boga Industri untuk Materi Kompetensi untuk SMK, LPK Pariwisata dan LPK Kapal Pesiar yang Siap Kerja. Penerbit Andi, Yogyakarta.

2. Novitasari, 2012. 25 Bisnis Sampingan untuk Karyawan, Langkah Cerdas untuk Membengkakkan Penghasilan sambil Tetap Bekerja. Andi Offset. Yogyakarta.

3. Layla TM, 2013. Bahan Berbahaya di Sekitar Kita. Penerbit Aqwamedika.

4. Kompas com, 2009. Kantong Plastic Kresek, Jangan Pakai Buat Wadah Makanan.

http://nasional.kompas.com/read/200 9/07/14/20375794/KantongPlastik Diakses 29 Maret 2018.

5. Kumparan, 2018. Bahaya plastik bagi kesehatan tubuh dan lingkungan. http://m.kumparan.com/tendirostendi/bahaya-plastik-bagikesehatan-tubuh-dan-lingkungan Diakses 29 April 2018.

6. Rahmadhani, 2015. Gambaran Pengetahuan dan Sikap dengan Posisi Tawar Konsumen tentang Penggunaan Kemasan Styrofoam sebagai Wadah Makanan dan Minuman Foodcourt Tahun 2015. Jurnal FKM USU, Medan http://download.portalgaruda.org/arti cle.php?... diakses 29 April 2018.

7. Setyowati, 2017. Studi Sifat Fisis, Kimia, Morfologi Pada Kemasan Makanan Berbahan Styrofoam Dan LDPE (Low Density Polyethylene) ;Telaah Kepustakaan. http://journal.eng.unila.ac.id/index.p hp/mech/article/viewFile/6/pdf. diakses 6 April 2018.

8. Damanik, 2012. Perilaku konsumen dalam penggunaan plastik kresek hitam daur ulang sebagai wadah siap santap di pusat pasar tavip binjai. Jurnal IPI Kesehatan. http://download.portalgaruda.org/arti cle.php?...diakses 29 Maret 2018.

9. Widyaningsih, F. 2010. Pengetahuan, sikap dan tindakan pemilik tempat makanan jajanan tentang penggunaan Styrofoam sebagai kemasan makanan di kelurahan padang bulanselayang 1 kecamatan medan selayang tahun 2010. Skripsi FKM USU. Medan.

10.

Ompusunggu, $\mathrm{H}$. 2009. Pengetahuan, Sikap Dan Tindakan Siswa Kelas X Tentang Bahaya Penggunaan Plastik Sebagai Tempat Makanan Dan Minuman Di SMU Negeri 14 Medan Tahun 2009. Skripsi FKM USU. Medan.

11. Ilmiawati, C.,dkk. 2017. Edukasi Pemakaian Plastik Sebagai Kemasan Makanan Dan Minuman Serta Resikonya Terhadap Kesehatan Pada Komunitas Di Kecamatan Bungus Teluk Kabung, Padang. Jurnal ilmiah pengabdian kepada masyarakat. Juni 2017, Vol 1(1):20-28. ISSN:25796283. Divisi Toksikologi Lingkungan. Universitas Andalas. Padang diakses pada tanggal 18 April 2018.

12. Ryady, 2016. Ilmu Kesehatan Masyarakat.

13. Notoatmodjo, S. 2011. Ilmu Kesehatan Masyarakat. Rineka Cipta, Jakarta.

14. Notoatmodjo, S. 2010. Metode Penelitian. Rineka Cipta, Jakarta.

15. Notoatmodjo, S. 2012. Promosi Kesehatan dan Perilaku Kesehatan. Penerbit Rineke Cipta. Jakarta.

16. Siregar, NY, 2011. Gambaran Perilaku Ibu Rumah Tangga Pengguna Wadah Plastik Penyimpanan Makanan dan 
Minuman di Kelurahan Sidorame Timur Kecamatan Medan Perjuangan Tahun 2011. http://repository.usu.ac.id/handle/123 456789/28814, diakses pada 29 Maret 2018.

17. Sumbung, 2012. Hubungan Antara Pengetaahuan Dan Sikap Dengan Tindakan Penjual Gorengan Di Kota Manado Dalam Mengurangi
Penggunaan Kantong Plastik. Fakultas kesehatan masyarakat universitas sam ratulangi.

18. Joewono, B.N, 2009. Hati-hati, plastic pembungkus bisa menyebabkan kanker. http://nasional.kompas.com/read/200 9/08/10/10363969/www.kompas.co m. diakses tanggal 29 Maret 2018. 


\section{LAMPIRAN}

Tabel [1]. Distribusi Responden Berdasarkan Umur

\begin{tabular}{cccc}
\hline No & Umur & Jumlah & Persentase \\
\hline 1 & $17-19$ & 88 & 59,86 \\
2 & $20-23$ & 59 & 40,13 \\
\hline & Jumlah & $\mathbf{1 4 7}$ & $\mathbf{1 0 0 \%}$ \\
\hline
\end{tabular}

Tabel [2]. Distribusi Responden Berdasarkan Jenis Kelamin

\begin{tabular}{|c|c|c|c|}
\hline No & Umur & Jumlah & Persentase \\
\hline 1. & Laki-laki & 27 & 18,37 \\
\hline 2. & Perempuan & 120 & 81,63 \\
\hline & Jumlah & 147 & $100 \%$ \\
\hline
\end{tabular}

Tabel [3]. Katagori Pengetahuan Responden Tentang Bahaya Penggunaan Plastik Sebagai Wadah Makanan Dan Minuman

\begin{tabular}{lccc}
\hline No & Katagori & Jumlah & Persentase \\
\hline 1. & Baik & 62 & 42,18 \\
2. & Sedang & 69 & 46,94 \\
3. & Kurang & 16 & 10.88 \\
\hline & Jumlah & $\mathbf{1 4 7}$ & $\mathbf{1 0 0 \%}$ \\
\hline
\end{tabular}

Tabel [4]. Katagori Sikap Responden Tentang Bahaya Penggunaan Plastik Sebagai Wadah Makanan Dan Minuman

\begin{tabular}{clcc}
\hline No & Katagori sikap & Jumlah & Persentase \\
\hline 1 & Positif & 95 & 64,63 \\
2 & Negatif & 52 & 35,37 \\
\hline & Jumlah & $\mathbf{1 4 7}$ & $\mathbf{1 0 0} \%$ \\
\hline
\end{tabular}

